J Am Chem Soc. 2016 January 27; 138(3): 1057-1064. doi:10.1021/jacs.5b12392.

\title{
Concise Total Synthesis of (+)-Asperazine, (+)-Pestalazine A, and $(+)$-iso-Pestalazine A. Structure Revision of (+)-Pestalazine A
}

\author{
Richard P. Loach, Owen S. Fenton, and Mohammad Movassaghi ${ }^{\star}$ \\ Department of Chemistry, Massachusetts Institute of Technology, Cambridge, Massachusetts \\ 02139, United States
}

\begin{abstract}
The concise, enantioselective total syntheses of (+)-asperazine (1), (+)-iso-pestalazine A (2), and (+)-pestalazine A (3) have been achieved by the development of a late-stage C3-C8' Friedel-Crafts union of polycyclic diketopiperazines. Our modular strategy enables the union of complex polycyclic diketopiperazines in virtually their final forms, thus providing rapid and highly convergent assembly at the challenging quaternary stereocenter of these dimeric alkaloids. The significance of this carbon-carbon bond formation can be gauged by the manifold constraints that were efficiently overcome, namely the substantial steric crowding at both reactive sites, the nucleophilic addition of $\mathrm{C}^{\prime}$ over $\mathrm{N}^{\prime}$ to the $\mathrm{C} 3$ carbocation, and the multitude of reactivity posed by the use of complex diketopiperazine fragments in the coupling event. The success of the indoline $\pi$-nucleophile that evolved through our studies is notable given the paucity of competing reaction pathways observed in the presence of the highly reactive $\mathrm{C} 3$ carbocation generated. This first total synthesis of (+)-pestalazine A also allowed us to revise the molecular structure for this natural alkaloid.
\end{abstract}

\begin{abstract}
The hexahydropyrroloindoles comprise a structurally and biologically fascinating class of alkaloid natural products. ${ }^{1}$ The dimeric diketopiperazine incarnations of these metabolites are replete with the sort of molecular complexity that regularly nourishes the advancement of new synthetic methodologies. ${ }^{2}$ Undeniably, the greatest obstacle for researchers seeking to gain efficient access to these structures has been the stereocontrolled introduction of the quaternary stereocenter and the carbon-carbon bond at the heart of these alkaloids. $(+)-$ Asperazine $(\mathbf{1})^{3}$ and its more recently isolated congener (+)-pestalazine $\mathrm{A}^{4}$ present an exemplary challenge for chemical synthesis by possessing heterodimeric diketopiperazines with a unique quaternary $\mathrm{C} 3_{\mathrm{sp} 3}-\mathrm{C} 8^{\prime}{ }_{\mathrm{sp} 2}$ juncture (Figure 1). While outstanding advances have been achieved in the synthesis of C3-aryl pyrroloindolines, ${ }^{5,6,7}$ Overman's elegant synthesis of (+)-asperazine (1) ${ }^{8}$ predicated on early introduction of the C3-quaternary stereocenter by an intramolecular Heck reaction ${ }^{9}$ followed by formation of the diketopiperazines, stands as the only solution to alkaloid (+)-1. Our highly convergent synthesis of the $\mathrm{C} 3-\mathrm{C} 7^{\prime}$ fused (+)-
\end{abstract}

\footnotetext{
*Corresponding Author: movassag@ mit.edu.

Notes

The authors declare no competing financial interests.

Supporting Information

Experimental procedures, spectroscopic data, and copies of NMR spectra. This material is available free of charge via the Internet at http://pubs.acs.org
} 
naseseazine alkaloids (Figure 1), ${ }^{10}$ prompted us to investigate the possibility of a complementary Friedel-Crafts based approach ${ }^{11}$ to alkaloids (+)-1-2, involving late-stage directed union of complex diketopiperazines, to secure the challenging $\mathrm{C} 3_{\mathrm{sp} 3}-\mathrm{C} 8^{\prime}{ }_{\mathrm{sp} 2}$ linkage. ${ }^{12}$ Herein, we report the development and implementation of this ambitious strategy to the highly expedient synthesis of (+)-asperazine (1), and the first total synthesis (+)-isopestalazine A (2) and (+)-pestalazine A (3). The culmination of our study was the revision and subsequent synthesis of the corrected structure of (+)-pestalazine A (3).

In recent years, various innovative methodologies have been formulated to address the synthesis of $\mathrm{C}_{\mathrm{sp} 3}-\mathrm{C} 3^{\prime}{ }_{\mathrm{sp} 3},{ }^{13,14,15,16} \mathrm{C}_{\mathrm{sp} 3}-\mathrm{N1} 1^{\prime 17}$ and $\mathrm{C} 3_{\mathrm{sp} 3}-$ arene $e^{5-9,11,12}$ bound pyrroloindolines. Our group has a long-standing interest in developing mild, versatile chemistries that can rapidly generate these complex, acutely sterically-congested C3 linkages in stereo- and regioselective fashion. ${ }^{2 \mathrm{c}}$ While many of the existing approaches to C3-aryl pyrroloindolines rely on alkylation of oxindoles, ${ }^{6}$ or rearrangement chemistry, ${ }^{7 \mathrm{~b}, \mathrm{~d}, \mathrm{f}, \mathrm{g}, \mathrm{k}}$ alternative methodologies have also been reported. ${ }^{7 \mathrm{a}, \mathrm{e}, \mathrm{h}-\mathrm{j}}$ Since our first report on diazene directed fragment assembly as a viable strategy for $\mathrm{C} 3$ arylation, ${ }^{16 a, b}$ much progress has also been made in the synthesis of C3-diazenyl pyrroloindolines. ${ }^{18}$ Recent advances in transition metal-catalyzed coupling methodologies have also provided exciting opportunities for the development of new routes to C3-aryl pyr-roloindolines. 5,19 The Overman group's Heck cyclization based strategy has proven especially successful in this arena, ${ }^{8,9}$ providing enantiomerically enriched $\mathrm{C} 3$-aryl oxindoles that paved the way for their landmark syntheses of C3-aryl pyrroloindoline alkaloids including (+)-asperazine (1), which was accomplished in 22 steps and $1.0 \%$ overall yield. $^{8}$

Our group has sought a different inroad into these heterodimers, based on a maximally convergent late-stage $\mathrm{C} 3$-arene coupling of advanced diketopiperazine intermediates. This tactic draws inspiration from biogenetic hypotheses on the origins of these natural products, ${ }^{20,21}$ but unlike the oxidative radical dimerizations,${ }^{7 \mathrm{i}}$ we found ionic unification pathways ${ }^{22}$ could better dictate regiocontrol at the C3-aryl juncture. ${ }^{12}$ Specifically, we developed a mild Friedel-Crafts-based method for the stereo- and regioselective addition of a wide range of nucleophiles to the $\mathrm{C} 3$ carbocation. ${ }^{23}$ Indolic interceptions at this benzylic cation, arising from mild silver activation of a bromide precursor, were instrumental in our expedient syntheses of the bionectins, gliocladins, and luteoalbusins. ${ }^{11}$ The ultimate demonstration of our late-stage heterodimerization paradigm came in our total syntheses of the $C 7^{\prime}$-linked (+)-naseseazines (i.e. 5 and 6, Figure 1). ${ }^{12}$ We now report our development of a powerful and enabling ortho-indoline-based Friedel-Crafts strategy that has led to a highly convergent, concise, regio- and stereocontrolled total synthesis of (+)-asperazine (1), (+)-isopestalazine A (2) and (+)-pestalazine A (3). This amplifies our group's repertoire of heterodimerization modes to now include late-stage $\mathrm{C}_{\mathrm{sp} 3}-\mathrm{C} 8^{\prime}{ }_{\mathrm{sp} 2}$ bond formation. A key feature of our routes to these targets is a newly-developed regioselective reductive ringopening reaction, which allowed the transposition of a more $\pi$-nucleophilic and regioselective indoline onto the eventual indole moiety, whilst simultaneously thwarting $\mathrm{N} 1^{\prime}$ and $\mathrm{C} 2^{\prime}$ nucleophilic attack.

As well as its initial discovery in minute quantities from a Caribbean sponge-derived culture of Aspergillus niger, (+)-asperazine (1) was also isolated in 2008 alongside (+)-pestalazine 
$\mathrm{A}(\mathbf{3})$ and the $\mathrm{C} 3_{\mathrm{sp} 3}-\mathrm{N} 1^{\prime}$ linked (+)-pestalazine B (4b, Figure 1) from the plant pathogenic fungus Pestalotiopsis theae. ${ }^{4}$ Interestingly, in a second exploration of extracts from Aspergillus niger, the $\mathrm{N1}^{\prime}$-linked isomer of (+)-asperazine (1), and congener of (+)pestalazine B (4b), (-)-asperazine A (4a) was also unearthed. ${ }^{24}$ Accordingly, considerations of the interrelated biogenetic origins of these alkaloids added further impetus to our desire for a synthesis (Scheme 1) that espoused late-stage, convergent assembly. Such a route would endow us with the utmost flexibility in rapidly accessing C3-C8'-bound structural variants of these fascinating natural products for future studies.

In our synthesis of the naseseazine alkaloids (Figure 1) the desired C3-arene connectivity was secured by deployment of an N1-protected C3-substituted indole (-)-8 (Scheme 1) that garnered $\pi$-nucleophilicity at its $\mathrm{C}^{\prime} / \mathrm{C}^{\prime}$ positions. ${ }^{12}$ Exclusive $\mathrm{C} 7^{\prime}$ Friedel-Crafts regioselection for product (-)-11 was ensured by use of trifluoroborate (-)-9, whose anionic directing group could facilitate tight ion pairing with the $\mathrm{C} 3$-derived cation from bromide (+)-10 (Scheme 1). ${ }^{12,25}$ Our initial retrosynthetic outlook (Scheme 2) for heterodimers (+)-1 and (+)-2 strived to achieve the same levels of regiocontrol by employing a $\mathrm{C} 8{ }^{\prime}-$ trifluoroborate 12, which could intercept tetracyclic carbocation 13. Bromide 15 would stem from diastereoselective bromocyclization of indole 16, procurable in decagram quantities from amino acid condensations of L-tryptophan. Our newly developed one pot protocol for the boronation of L-tryptophans also prompted us to consider $\mathrm{C} 8$ '-boroindole derivatives $\mathbf{1 2}$ and $14 .^{26}$

The pronounced challenges that met our plan to switch from $\mathrm{C}^{\prime}$ to $\mathrm{C} 8^{\prime}$ indole for $\mathrm{C} 3$ addition were borne out by our initial studies into directing $\pi$-nucleophilicity to this position. From the outset, unlike the naseseazines, the unfeasibility of using N1-protected indoles for C 8 '-directed Friedel-Crafts coupling presented added complications. ${ }^{27}$ Notably, attempts at Miyaura boronation of N1-protected 8-bromotryptophans failed to provide the corresponding C8-boronotryptophan. ${ }^{28}$ Conversely, N1-functionalization post-C8 boronation of tryptophans proved equally ineffective. With facile access to trifluoroborate $(+)-17 \mathbf{a}$ on a multigram scale from the pinacol precursor, ${ }^{26}$ we were able to explore FriedelCrafts conditions for its reaction with bromide (+)-18a. This bromide was itself readily attained in one step through bromocyclization of the corresponding diketopiperazine (vide infra) in a manner akin to our previous synthetic campaigns. ${ }^{11,12,14}$ Thus, by employing silver(I) hexafluoroantimonate in conjunction with 18-crown-6 and 2,6-di-tert-butyl-4methylpyridine (DTBMP), ${ }^{29}$ we were able to obtain $6 \%$ yield of the desired product, $\mathrm{C}^{\prime}$ linked indole (+)-19a, but this was compounded by the presence of the $\mathrm{C}^{\prime}$ - and $\mathrm{C}^{\prime}$-linked regioisomers in similar quantities (Scheme 3) ${ }^{29,30}$ We next considered blocking these two undesired positions by introducing reductively removable substituents, ${ }^{11 \mathrm{a}}$ in the form of 6bromo-2-chloroindole (+)-17b ${ }^{29}$ The reaction of trifluoroborate (+)-17b with bromide $(+)-\mathbf{1 8 a}$ gave fewer side products, with $22 \%$ yield of adduct $(+)-\mathbf{1 9 b}{ }^{31}$ This low yield of the desired $C 8^{\prime}$-linked indole indicated that the underlying problem of poor $\pi$-nucleophilicity at $\mathrm{C} 8^{\prime}$ had persisted despite the use of a directing trifluoroborate. ${ }^{12,25 \mathrm{c}}$ In spite of this, dimer (+)-19 could be carried forward (Scheme 3) to (+)-asperazine (1) via indoline (+)-20. ${ }^{29}$ Importantly, this unoptimized first-generation synthesis allowed us to establish the critical heterodimeric $\mathrm{C} 8^{\prime}-\mathrm{C} 3$ bond. ${ }^{29}$ The parity of our data with that of Overman's previous 
synthesis ${ }^{8}$ also retrospectively confirmed the regio- and stereochemical outcome of our first generation solution for securing the quaternary stereocenter and the challenging $\mathrm{C}_{\mathrm{sp} 3}-$ $\mathrm{C} 8^{\prime}{ }_{\mathrm{sp} 2}$ bond.

These observations set the foundation for our development of a second generation C3-C8' coupling strategy focused on enhancing $\mathrm{C} 8^{\prime}$ reactivity and thereby suppress formation of regioisomeric and oligomeric side products. Central to this new approach was the utility of a reversible cyclization of tryptophan-derived diketopiperazines. Since tryptophan-derived diketopiperazines are known to cyclize reversibly in acid to their tetracyclic forms, ${ }^{32}$ our concerns could be addressed by temporarily locking this equilibrium at bis-indoline $\mathbf{2 1}$ (Scheme 4). From a retrosynthetic perspective, this would allow us to harness the superior $\pi-$ nucleophilicity of an aniline moiety for Friedel-Crafts chemistry and simultaneously remove $\mathrm{C} 2$ ' nucleophilicity. The subsequent unlocking of bis-indoline 21 could be achieved post$\mathrm{C} 8$ '-C3 bond formation, by $\mathrm{C} 3$ ' ionization-reduction of alcohol $\mathbf{2 2}$. This alcohol would act as a stable surrogate of dimer 21, and originate from ortho Friedel-Crafts coupling of indoline $\mathbf{2 3}$ to $\mathrm{C} 3$-bromide $\mathbf{2 4}$. In order to maximize the propensity for $\mathrm{C}^{\prime}$ addition of indoline 23, it was crucial from consideration of steric as well as electronic factors, to forego any form of N1 protection. Critical to our plan's success was the notion that the N1 position of tetracycle $\mathbf{2 3}$ would be too sterically encumbered to itself add efficiently to the $\mathrm{C} 3$ electrophile. ${ }^{33}$ Again, both Friedel-Crafts components $\mathbf{2 3}$ and $\mathbf{2 4}$ could be fashioned via halocyclization of the necessary indolic diketopiperazines $\mathbf{1 6}$, thus preserving the expediency of our previous route.

Knowledge from our prior synthetic campaigns pointed to conditions for $\mathrm{C} 3$ bromide ionization being milder in the presence of a carboxybenzyl over a sulfonyl N1 substituent. ${ }^{11,12,14}$ The synthesis of the tetracyclic diketopiperazine intermediates therefore began with readily available $N^{\mathrm{a}}$-Boc- $N$-Cbz-L-tryptophan methyl ester and its straightforward conversion to diketopiperazines (+)-26a and (+)-26b, via dipeptide selfcondensation in $80 \%$ and $83 \%$, respectively. ${ }^{29}$ Initial attempts to obtain tetracyclic bromide (+)-18a via diastereoselective bromocyclization of indole ${ }^{11 b, 12}(+)-26 \mathbf{a}$ were hampered by poor solubility of these diketopiperazines in various organic solvents. Exposure of diketopiperazine (+)-26a to our standard procedure involving an equivalent of bromine in dichloromethane, ${ }^{12}$ benzene, ${ }^{11 \mathrm{~b}}$ or acetonitrile, ${ }^{11 \mathrm{c}, \mathrm{d}}$ gave the desired bromide (+)-18a in < $30 \%$ yield. ${ }^{34}$ This yield was substantially improved by addition of two equivalents of boron trifluoride to a slurry of precursor (+)-26a in acetonitrile prior to bromonium ion formation. To this end, the use of $N$-bromosuccinimide in place of bromine was found to result in a superior endo/exo ratio, and we were able to synthesize the versatile bromides (+)-18a and $(+)-18 b$ on a gram scale in $63 \%$ and $66 \%$ yield, respectively. Scaling the conditions to $15 \mathrm{~g}$ of diketopiperazine (+)-26a afforded bromide (+)-18a in 59\% yield (Scheme 5).

In order to induce ortho (C8) selectivity in the Friedel-Crafts coupling, the para position (C6) on the eventual nucleophile $\mathbf{2 3}$ (Scheme 4) was temporarily blocked. ${ }^{11 a}$ After screening various Lewis and Brønsted acids in combination with $\mathrm{N}$-chlorosuccinimide, the inclusion of trifluoroacetic acid ${ }^{35}$ for bromide (+)-18a, or titanium(IV) tetrachloride in the case of bromide (+)-18b, led to $94 \%$ and $90 \%$ yield, respectively, of the corresponding C6chlorinated tetracycles (+)-27a and (+)-27b (Scheme 5). We were pleased to note that the 
presence of this C6-chlorine had no deleterious effect on silver(I)-promoted C3 bromide ionization, as shown by the rapid conversion of indolines (+)-27a and (+)-27b to hydrates $(+)-28 \mathbf{a}$ and (+)-28b in respective yields of $96 \%$ and $93 \%$. Their conversion to silyl ethers $(+)-29 \mathbf{a}$ and (+)-29b on multigram scale was then followed by efficient and mild palladiumcatalyzed carboxybenzyl removal, ${ }^{36}$ with no sign of dehalogenation,,${ }^{12}$ providing the desired indolines (+)-30a and (+)-30b (Scheme 5). The C3-hydroxyl could function as a stable placeholder, effectively locking in the cyclotryptamine substructure during the Lewis acidpromoted Friedel-Crafts step, later to be ionized and reduced under Brønsted acidic conditions.

Having firmly established the route to our designed nucleophilic and electrophilic FriedelCrafts components (Scheme 5) for both alkaloid targets, now accessible in multigram quantities, we were well positioned to explore the key fragment-coupling step. Initial forays involving exposure of bromide (+)-18a to silver(I) hexafluoroantimonate, in the presence of indoline (+)-30a in nitroethane, led to 5-10\% yield of C3-C 8 -coupled product. Importantly, we were pleased to observe virtually no $\mathrm{N1}^{\prime}$-linked heterodimeric products. However, as before, mixtures of side products, largely attributable to competing para-directed oligomerizations of precursor (+)-18a, were still observed. Gratifyingly, replacement of tetracycle (+)-18a with its 6-chlorinated counterpart (+)-27a resulted in excellent mass balance, with the undesirable oligomerizations being mostly suppressed. Under our optimal silver(I) activation conditions, ${ }^{29}$ the desired heterodimeric indoline (+)-31a was isolated in $41 \%$ yield, along with $24 \%$ of recovered starting material (+)-30a, and $30 \%$ of alcohol (+)-28a (Scheme 6), stemming from bromide (+)-27a.

Notably, treatment of recovered alcohol (+)-28a with thionyl bromide regenerated electrophile (+)-27a in near quantitative yields (Scheme 5), meaning both Friedel-Crafts partners (+)-30a and (+)-27a could be recycled to produce more of bis-indoline (+)-31a. The degree of molecular complexity and congested nature of the quaternary $\mathrm{C} 3-\mathrm{C} 8^{\prime}$ bond being rapidly formed in a single step, under mild conditions, make this Friedel-Crafts reaction (Scheme 6) an exciting prospect for future applications in related natural and designed complex molecule syntheses. Two-dimensional NMR analysis provided decisive HMBC and NOESY correlations in support of our structural assignment of bis-indoline (+)-31a (Scheme 6 ). Nonetheless, our ability to swiftly convert this dimer to alkaloid (+)-1 offered confirmation of the $\mathrm{C} 3-\mathrm{C} 8^{\prime}$ dimeric linkage. We had originally envisaged relying on the N1 protection of dimer (+)-31a as a means for ensuring selective reopening of only the $\mathrm{N} 1{ }^{\prime}$ free indoline to the desired indole moiety. However, desilylation of ether (+)-31a proved ineffective with all but nucleophilic fluorides, which caused minor amounts of epimerization. ${ }^{37}$ We eventually found that by first performing a combined hydrogenolysis and bis-dehalogenation on substrate (+)-31a to provide silyl ether (+)-32a in 79\% yield (Scheme 6), the ensuing silyl cleavage could proceed without incident. To this end, treatment of dimer (+)-32a with tris(dimethylamino)sulfonium difluorotrimethylsilicate (TASF) provided alcohol (+)-33a in $90 \%$ yield. ${ }^{38}$

With intermediate (+)-33a in hand, we were able to investigate a range of conditions for the penultimate tandem $\mathrm{C}^{\prime}$ ' reduction-ring opening step to arrive at alkaloid (+)-1 (Scheme 6). 
After examining various conditions, the highest yield of (+)-asperazine (1, 67\%, Scheme 6) was attained by a combination of triethylsilane with methanesulfonic acid. Based on our previous thiolation studies for the syntheses of epipolythiodiketopiperazine alkaloids, ${ }^{11,14 \mathrm{c}-\mathrm{d}}$, trifluoroacetic acid was originally chosen for $\mathrm{C} 3^{\prime}$ ionization. However, when utilizing triethylsilane in conjunction with this acid, only a modest yield (40\%) of (+)asperazine (1) could be isolated, despite complete consumption of alcohol (+)-33a after 24 h. Though we reasoned that a substantial Thorpe-Ingold constraint should inhibit acidcatalyzed opening of the southern tetracycle, the recovery of water-soluble diketopiperazine side products from this experiment led us to infer that such a destructive pathway was enhanced by prolonged exposure to acid, as well as silane reduction of the indole moiety. ${ }^{39}$ This conclusion was corroborated when substitution with methanesulfonic acid led to shorter reaction times and the improved yield of (+)-asperazine (1, Scheme 6$)$. We were pleased to observe that all spectroscopic data for (+)-asperazine (1), along with its optical rotation, were in complete accord ${ }^{29}$ with that of Overman's synthetic (+)-asperazine, ${ }^{8}$ and the isolated metabolite. ${ }^{3}$

Having successfully employed this modular strategy to our highly convergent synthesis of $(+)$-asperazine (1), the stage was now set for us to tackle the first total synthesis of (+)pestalazine A (2). We began by replacing indoline (+)-30a with its D-leucine counterpart $(+)-\mathbf{3 0 b}$, and under the same silver-mediated conditions to ionize bromide (+)-27a, obtained the corresponding heterodimer $(+)-31 \mathbf{b}$ in $48 \%$ yield. ${ }^{29}$ The improved yield in this reaction we attributed to the higher reaction concentrations attained using substrate (+)-30b, which was more soluble in nitroethane than indoline (+)-30a. The subjection of bis-chlorinated dimer (+)-31b to hydrodehalogenation provided silyl ether (+)-32b in $84 \%$ yield. The ensuing desilylation with tetrabutylammonium fluoride also proceeded without incident to furnish alcohol (+)-33b in $91 \%$ yield. Exposure of this intermediate to our optimal reduction-ring opening protocol, namely methanesulfonic acid and triethylsilane, delivered indole (+)-2 in $73 \%$ yield (Scheme 6).

Our completion of this synthesis allowed for conclusive comparisons to be made between the structural data of alkaloid (+)-2 and the isolation data originally reported by Che and coworkers for natural (+)-pestalazine A. ${ }^{4}$ The ${ }^{1} \mathrm{H}$ and ${ }^{13} \mathrm{C}$ NMR signals corresponding to the positions around the indole and indoline portions of our molecule were in excellent agreement with the isolation report $\left(<0.5 \mathrm{ppm}\right.$ difference between ${ }^{13} \mathrm{C}$ NMR signals $),{ }^{29}$ thereby confirming the crucial $\mathrm{C} 3-\mathrm{C} 8^{\prime}$ connectivity. However, the same could not be said of several key ${ }^{1} \mathrm{H}$ signals corresponding to the diketopiperazine moieties, which differed markedly from the values in the isolation report, specifically the C11 $\left(3.37^{29}\right.$ vs. $\left.4.68^{4} \mathrm{ppm}\right)$, $\mathrm{C} 15$ (4.10 ${ }^{29}$ vs. $\left.3.25^{4} \mathrm{ppm}\right), \mathrm{C} 11^{\prime}\left(4.16^{29}\right.$ vs. $\left.3.46^{4} \mathrm{ppm}\right)$ and $\mathrm{C} 15^{\prime}\left(3.03^{29}\right.$ vs. $\left.3.80^{4} \mathrm{ppm}\right)$ positions (Scheme 6). Furthermore, indole (+)-2, which we now came to regard as (+)-isopestalazine A, exhibited an optical rotation of $+99^{\circ}(c 0.17, \mathrm{MeOH}),{ }^{29}$ as compared to Che's value of $+203^{\circ}(c 0.10, \mathrm{MeOH})^{4}$ for natural (+)-pestalazine $\mathrm{A}$.

This propitious discovery would thus provide the ideal platform to demonstrate the power of our modular Friedel-Crafts approach to $\mathrm{C} 3-\mathrm{C} 8$ ' coupling. Without any change to our synthetic route, we pursued an alternative structural isomer of dimer (+)-2, in which the northern and southern diketopiperazines were inverted (Figure 1). We believed this reversal 
of top and bottom monomers to be highly plausible given that (+)-pestalazine A would be expected to share a similar biogenetic origin to (+)-pestalazine B $(\mathbf{4 b})$, which had undergone structural revision during its synthesis. ${ }^{17 \mathrm{~g}}$ Our hypothesis was further substantiated by the more recent discovery of (+)-asperazine (1) along with its $\mathrm{N1}^{\prime}$-linked isomer (-)-asperazine A (4a) ${ }^{24}$ The facility with which we could simply switch the top and bottom monomers in our key Friedel-Crafts step (Scheme 7) proved decisive in enabling us to rapidly elucidate the structure that validated the data from the metabolite's isolation report.

With the necessary Friedel-Crafts components, indoline (+)-30a and bromide (+)-27b, already in hand (Scheme 5), we were able to direct the union of these tetracycles in formation of dimer (+)-31c in 32\% yield (Scheme 7). In this case, we only deviated from our established conditions by including dichloromethane as co-solvent during fragment assembly. This allowed us to work at higher reaction concentrations while maintaining the optimal reactivity that nitroethane had consistently provided. The recovered starting material $(+)-30 \mathbf{a}$ and the side product alcohol (+)-28b could be recycled, the latter by its conversion back to bromide (+)-27b in $98 \%$ yield by subjection to thionyl bromide and 2,6-di-tertbutyl-4-methylpyridine (Scheme 5). ${ }^{29} \mathrm{Next}$, concomitant carboxybenzyl hydrogenolysis and bis-dechlorination of dimeric substrate (+)-31c, followed by desilylation of ether (+)-32c, proceeded in $69 \%$ and $91 \%$ yield, respectively (Scheme 7). The final reduction and ringopening of alcohol (+)-33c furnished indole (+)-3 in $71 \%$ yield. To our delight, all spectroscopic data for molecule (+)-3 were in excellent agreement with those from Che's isolation report of (+)-pestalazine $\mathrm{A},{ }^{4}$ thereby confirming (+)-3 as the correct structure. Furthermore, the optical rotation for $(+)-3$ was $+211^{\circ}(c 0.13, \mathrm{MeOH})^{29}$ which was in good agreement with the reported value for the natural isolate. ${ }^{4}$

In summary, we completed expedient and unified total syntheses of (+)-asperazine (1), (+)iso-pestalazine (2), and (+)-pestalazine A (3), in eleven steps from commercially available $N$-Boc-L-tryptophan methyl ester, and respective overall yields of $6.8 \%, 8.0 \%$ and $4.8 \%$. Guided by our core ethos of retrobio-synthetic ${ }^{2 c, 40}$ analysis, we developed a mild, regioand stereocontrolled, ortho-directed Friedel-Crafts reaction for the formation of the critical C3-C8' dimeric linkage in these molecules. Our late-stage $\mathrm{C} 3-\mathrm{C} 8$ ' heterodimerization approach to structures (+)-1, (+)-2 and (+)-3 benefits from its use of advanced diketopiperazine tetracycles as easily interconvertible Friedel-Crafts components. The successful implementation of this new and convergent synthetic strategy for these dimeric diketopiperazines required the application of the new tandem $\mathrm{C}^{\prime}$ reduction-ring opening transformation for the selective late-stage unraveling of the tryptophan motif in these alkaloids. Additionally, the generality of our three-step protocol from Friedel-Crafts product (+)-31 to the final alkaloids was showcased by our ability to employ the same sequence with all three natural product targets. This paved the way for a modular, highly convergent strategy that allowed for a facile inversion of the tetracyclic fragments in (+)-iso-pestalazine (2) to (+)-pestalazine (3). The first total synthesis of (+)-pestalazine A (3) led to a revision of its structure from the originally reported polycyclic indole $(+)-2$. Our biogenetically inspired synthetic strategy to these fascinating alkaloids described here expands the range of heterodimeric diketopiperazines accessible by highly stereo- and regioselective late-stage complex fragment assembly. 


\section{Supplementary Material}

Refer to Web version on PubMed Central for supplementary material.

\section{Acknowledgments}

We acknowledge financial support by NIH-NIGMS (GM089732) and Amgen. R.P.L. thanks the Fonds de Recherche du Québec, Nature et Technologies for a postdoctoral fellowship.

\section{References}

1. (a) Cordell, GA.; Saxton, JE. The Alkaloids: Chemistry and Physiology. Manske, RHF.; Rodrigo, RGA., editors. Vol. 20. Academic Press; New York: 1981. p. 3-295.(b) Hino, T.; Nakagawa, M. The Alkaloids: Chemistry and Pharmacology. Brossi, A., editor. Vol. 34. Academic Press; New York: 1989. p. 1-75.(c) Sevenet, T.; Pusset, J. The Alkaloids: Chemistry and Pharmacology. Cordell, GA., editor. Vol. 48. Academic Press; New York: 1996. p. 1-73.(d) Anthoni, U.; Christophersen, C.; Nielsen, PH. Alkaloids: Chemical and Biological Perspectives. Pelletier, SW., editor. Vol. 13. Pergamon; London: 1999. p. 163-236.

2. (a) Borthwick AD. Chem Rev. 2012; 112:3641. [PubMed: 22575049] (b) Tadano S, Ishikawa H. Synlett. 2014; 25:157.(c) Kim J, Movassaghi M. Acc Chem Res. 2015; 48:1159. [PubMed: 25843276]

3. Varoglu M, Corbett TH, Valeriote FA, Crews P. J Org Chem. 1997; 62:7078. [PubMed: 11671801]

4. Ding G, Jiang L, Guo L, Chen X, Zhang H, Che Y. J Nat Prod. 2008; 71:1861. [PubMed: 18855443]

5. (a) Zhu S, MacMillan DWC. J Am Chem Soc. 2012; 134:10815. [PubMed: 22716914] (b) Kieffer ME, Chuang KV, Reisman SE. Chem Sci. 2012; 3:3170. [PubMed: 23105962] (c) Kieffer ME, Chuang KV, Reisman SE. J Am Chem Soc. 2013; 135:5557. [PubMed: 23540731] (d) Wang X, Wang S, Xue W, Gong H. J Am Chem Soc. 2015; 137:11562. [PubMed: 26325479]

6. (a) Pei XF, Greig NH, Brossi A. Heterocycles. 1998; 49:437.(b) Ma S, Han X, Krishan S, Virgil SC, Stoltz BM. Angew Chem, Int Ed. 2009; 48:8037.(c) He R, Ding C, Maruoka K. Angew Chem, Int Ed. 2009; 48:4559.(d) Li X, Luo S, Cheng JP. Chem-Eur J. 2010; 16:14290. [PubMed: 21117044] (e) Li P, Buchwald SL. Angew Chem, Int Ed. 2011; 50:6396.(f) Zhou Y, Zhao Y, Dai X, Liu J, Li L, Zhang H. Org Biomol Chem. 2011; 9:4091. [PubMed: 21472186] (g) Chen W, Yang W, Yan L, Tan CH, Jiang Z. Chem Commun. 2013; 49:9854.(h) Liu R, Zhang J. Org Lett. 2013; 15:2266. [PubMed: 23617230] (i) Repka LM, Reisman SE. J Org Chem. 2013; 78:12314. [PubMed: 24295135] (j) Kinthada LK, Ghosh S, Badu KN, Sharique M, Biswas S, Bisai A. Org Biomol Chem. 2014; 12:8152. [PubMed: 25179466] (k) Awata A, Wasai M, Masu H, Kado S, Arai T. Chem-Eur J. 2014; 20:2470. [PubMed: 24519992] (1) Zhang FL, Zhu X, Chiba S. Org Lett. 2015; 17:3138. [PubMed: 26067162]

7. (a) Crich D, Fredette E, Flosi WJ. Heterocycles. 1998; 48:545.(b) Magnus P, Turnbull R. Org Lett. 2006; 8:3497. [PubMed: 16869644] (c) Crich D, Banerjee A. Acc Chem Res. 2007; 40:151. [PubMed: 17309195] (d) Movassaghi M, Schmidt MA, Ashenhurst JA. Org Lett. 2008; 10:4009. [PubMed: 18722452] (e) Boal BW, Schammel AW, Garg NK. Org Lett. 2009; 11:3458. [PubMed: 19601608] (f) Duguet N, Slawin AMZ, Smith AD. Org Lett. 2009; 11:3858. [PubMed: 19645426] (g) DeLorbe JE, Jabri SY, Mennen SM, Overman LE, Zhang FL. J Am Chem Soc. 2011; 133:6549. [PubMed: 21473649] (h) Furst L, Narayanam JMR, Stephenson CRJ. Angew Chem, Int Ed. 2011; 50:9655.(i) Tadano S, Mukaeda Y, Ishikawa H. Angew Chem, Int Ed. 2013; 52:7990.(j) Beaud R, Guillot R, Kouklovsky C, Vincent G. Chem-Eur J. 2014; 20:7492. [PubMed: 24828464] (k) Tomakinian T, Kouklovsky C, Vincent G. Synlett. 2015; 26:1269.

8. (a) Govek SP, Overman LE. J Am Chem Soc. 2001; 123:9468. [PubMed: 11562240] (b) Govek SP, Overman LE. Tetrahedron. 2007; 63:8499.

9. (a) Lebsack AD, Link JT, Overman LE, Stearns BA. J Am Chem Soc. 2002; 124:9008. [PubMed: 12148978] (b) Kodanko JJ, Overman LE. Angew Chem, Int Ed. 2003; 42:2528.(c) Overman LE, Peterson EA. Angew Chem, Int Ed. 2003; 42:2525.(d) Dounay AB, Hatanaka K, Kodanko JJ, Oestreich M, Overman LE, Pfeifer LA, Weiss MM. J Am Chem Soc. 2003; 125:6261. [PubMed: 12785859] (e) Overman LE, Dounay A. Chem Rev. 2003; 103:2945. [PubMed: 12914487] (f) 
Mason A, O’Donnell CJ, Oh T, Old DW, Overman LE, Sharp MJ. J Am Chem Soc. 2005; 127:18054. [PubMed: 16366557] (g) Steven A, Overman LE. Angew Chem, Int Ed. 2007; 46:5488.

10. Raju R, Piggott AM, Conte M, Aalbersberg WGL, Feussner K, Capon RJ. Org Lett. 2009; 11:3862. [PubMed: 19655766]

11. (a) Boyer N, Movassaghi M. Chem Sci. 2012; 3:1798. [PubMed: 22844577] (b) Boyer N, Morrison KC, Kim J, Hergenrother PJ, Movassaghi M. Chem Sci. 2013; 4:1646. [PubMed: 23914293] (c) Coste A, Kim J, Adams TC, Movassaghi M. Chem Sci. 2013; 4:3191. [PubMed: 23878720] (d) Adams TC, Payette JN, Cheah JH, Movassaghi M. Org Lett. 2015; 17:4268. [PubMed: 26336940]

12. Kim J, Movassaghi M. J Am Chem Soc. 2011; 133:14940. [PubMed: 21875056]

13. (a) Hendrickson JB, Rees R, Goschke R. Proc Chem Soc. 1962:383.(b) Hino T, Yamada S. Tetrahedron Lett. 1963; 4:1757.(c) Scott AI, McCapra F, Hall ES. J Am Chem Soc. 1964; 86:302. (d) Nakagawa M, Sugumi H, Kodato S, Hino T. Tetrahedron Lett. 1981; 22:5323.(e) Fang CL, Horne S, Taylor N, Rodrigo R. J Am Chem Soc. 1994; 116:9480.(f) Link JT, Overman LE. J Am Chem Soc. 1996; 118:8166.(g) Overman LE, Paone DV, Stearns BA. J Am Chem Soc. 1999; 121:7702.(h) Somei M, Osikiri N, Hasegawa M, Yamada F. Heterocycles. 1999; 51:1237.(i) Overman LE, Larow JF, Stearns BA, Vance JM. Angew Chem, Int Ed. 2000; 39:213.(j) Ishikawa H, Takayama H, Aimi N. Tetrahedron Lett. 2002; 43:5637.(k) Verotta L, Orsini F, Sbacchi M, Scheildler MA, Amador TA, Elisabetsky E. Bioorg Med Chem. 2002; 10:2133. [PubMed: 11983509] (1) Matsuda Y, Kitajima M, Takayama H. Heterocycles. 2005; 65:1031.(m) Menozzi C, Dalko PI, Cossy J. Chem Commun. 2006; 44:4638.(n) Guo C, Song J, Huang JZ, Chen PH, Luo SW, Gong LZ. Angew Chem, Int Ed. 2012; 51:1046.(o) Peng Y, Luo L, Yan CS, Zhang JJ, Wang YW. J Org Chem. 2013; 78:10960. [PubMed: 24087851] (p) Tayu M, Higuchi K, Ishizaki T, Kawasaki T. Org Lett. 2014; 16:3613. [PubMed: 24988177] (q) Wada M, Murata T, Oikawa H, Oguri H. Org Biomol Chem. 2014; 12:298. [PubMed: 24217772] (r) Ghosh S, Chaudhuri S, Bisai A. Org Lett. 2015; 17:1373. [PubMed: 25745809] (s) Sanzone A, Somfai P. Eur J Org Chem. 2015; 16:3441.(t) Liang K, Deng X, Tong X, Li D, Ding M, Zhou A, Xia C. Org Lett. 2015; 17:206. [PubMed: 25565384]

14. For cobalt-mediated C3 homodimerization, see: Movassaghi M, Schmidt MA. Angew Chem, Int Ed. 2007; 46:3725.Movassaghi M, Schmidt MA, Ashenhurst JA. Angew Chem, Int Ed. 2008; 47:1485.Kim J, Ashenhurst J, Movassaghi M. Science. 2009; 324:238. [PubMed: 19359584] Kim J, Movassaghi M. J Am Chem Soc. 2010; 132:14376. [PubMed: 20866039]

15. For recent applications of our cobalt-mediated C3 homodimerization, see: Perez-Balado C, de Lera AR. Org Lett. 2008; 10:3701. [PubMed: 18680309] Perez-Balado C, Rodríguez-Graña P, de Lera AR. Chem-Eur J. 2009; 15:9928. [PubMed: 19681075] Iwasa E, Hamashima Y, Fujishiro S, Higuchi E, Ito A, Yoshida M, Sodeoka M. J Am Chem Soc. 2010; 132:4078. [PubMed: 20210309] Foo K, Newhouse T, Mori I, Takayama H, Baran PS. Angew Chem, Int Ed. 2011; 50:2716.Iwasa E, Hamashima Y, Fujishiro S, Hashizume D, Sodeoka M. Tetrahedron. 2011; 67:6587.Xie W, Jiang G, Liu H, Hu J, Pan X, Zhang H, Wan X, Lai Y, Ma D. Angew Chem, Int Ed. 2013; 52:12924.Canham SM, Hafensteiner BD, Lebsack AD, May-Dracka TL, Nam S, Stearns BA, Overman LE. Tetrahedron. 2015; 71:6424. [PubMed: 26257440]

16. For heterocoupling via diazene fragmentation, see: Movassaghi M, Ahmad OK, Lathrop SP. J Am Chem Soc. 2011; 133:13002. [PubMed: 21761893] Lathrop SP, Kim J, Movassaghi M. Chimia. 2012; 66:389. [PubMed: 22871281] Lathrop SP, Movassaghi M. Chem Sci. 2014; 5:333.

17. (a) Newhouse T, Baran PS. J Am Chem Soc. 2008; 130:10886. [PubMed: 18656919] (b) Espejo VR, Rainier JD. J Am Chem Soc. 2008; 130:12894. [PubMed: 18774822] (c) Matsuda Y, Kitajima M, Takayama H. Org Lett. 2008; 10:125. [PubMed: 18069843] (d) Newhouse T, Lewis CA, Baran PS. J Am Chem Soc. 2009; 131:6360. [PubMed: 19374357] (e) Espejo VR, Li XB, Rainier JD. J Am Chem Soc. 2010; 132:8282. [PubMed: 20518467] (f) Espejo VR, Rainier JD. Org Lett. 2010; 12:2154. [PubMed: 20345161] (g) Perez-Balado C, De Lera AR. Org Biomol Chem. 2010; 8:5179. [PubMed: 20848034] (h) Villanueva-Margalef I, Thurston DE, Zinzalla G. Org Biomol Chem. 2010; 8:5294. [PubMed: 20856944] (i) Rainier JD, Espejo VR. Isr J Chem. 2011; 51:473. (j) Zhang Z, Antilla JC. Angew Chem, Int Ed. 2012; 51:11778.(k) Cui BD, You Y, Zhao JQ, Zuo J, Wu ZJ, Xu XY, Zhang XM, Yuan WC. Chem Commun. 2015; 51:757.(1) Tayu M, Ishizaki T, Higuchi K, Kawasaki T. Org Biomol Chem. 2015; 13:3863. [PubMed: 25714899]

18. (a) Nelson HM, Reisberg SH, Shunatona HP, Patel JS, Toste FD. Angew Chem, Int Ed. 2014; 53:5600.(b) Stephens DE, Larionov OV. Eur J Org Chem. 2014:3662. 
19. For development of diaryliodonium-based arylation via Cu-catalysis, see: Phipps RJ, Grimster NP, Gaunt MJ. J Am Chem Soc. 2008; 130:8172. [PubMed: 18543910] Bigot A, Williamson AE, Gaunt MJ. J Am Chem Soc. 2011; 133:13778. [PubMed: 21848264] Phipps RJ, McMurray L, Ritter S, Duong HA, Gaunt MJ. J Am Chem Soc. 2012; 134:10773. [PubMed: 22712572] . For development of Ni-based arylation, see Zultanski S, Fu GC. J Am Chem Soc. 2013; 135:624. and references therein. [PubMed: 23281960]

20. For hypotheses on dimeric cyclotryptamine biosynthesis, see: Robinson R, Teuber HJ. Chem Ind. 1954:783. Woodward RB, Yang NC, Katz TJ, Clark VM, Harley-Mason J, Ingleby RFJ, Sheppard N. Proc Chem Soc. 1960:76.. For labeling and biosynthetic studies, see: Schutte HR, Maier B. Arch Pharm. 1965; 298:459.O’Donovan DG, Keogh MF. J Chem Soc C. 1966:1570.Kirby GW, Shah SW, Herbert EJ. J Chem Soc C. 1969:1916.

21. For reviews, see: Schmidt MA, Movassaghi M. Synlett. 2008; 21:313.Kim J, Movassaghi M. Chem Soc Rev. 2009; 38:3035. [PubMed: 19847339]

22. For a plausible cation-mediated dimerization hypothesis, see page S3 of ref. ${ }^{12}$.

23. For seminal work on the stereoretentive alkylations of a C3-derived cyclotryptophan carbocation, see Marsden SP, Depew KM, Danishefsky SJ. J Am Chem Soc. 1994; 116:11143. and references therein.

24. Li X-B, Li Y-L, Zhou J-C, Yuan H-Q, Wang X-N, Lou H-X. J Asian Nat Prod Res. 2015; 17:182. [PubMed: 25401948]

25. (a) Petasis NA, Akritopoulou I. Tetrahedron Lett. 1993; 34:583.(b) Mayr H, Bug T, Gotta MF, Hering N, Irrgang B, Janker B, Kempf B, Loos R, Ofial AR, Remennikov G, Schimmel H. J Am Chem Soc. 2001; 123:9500. [PubMed: 11572670] (c) Lee S, MacMillan DWC. J Am Chem Soc. 2007; 129:15438. [PubMed: 18031044]

26. Loach RP, Fenton OS, Amaike K, Siegel DS, Ozkal E, Movassaghi M. J Org Chem. 2014; 79:11254. [PubMed: 25343326]

27. The steric and electronic factors that inhibited $\mathrm{C} 2^{\prime}$ addition with $\mathrm{N} 1$-carboxybenzyl containing substrates in our naseseazines campaign seem to prohibit $\mathrm{C} 8^{\prime}-\mathrm{C} 3$ coupling in the present study.

28. (a) Ishiyama T, Murata M, Miyaura N. J Org Chem. 1995; 60:7508.(b) Billingsley KL, Barder TE, Buchwald SL. Angew Chem, Int Ed. 2007; 46:5359.(c) Billingsley KL, Buchwald SL. J Org Chem. 2008; 73:5589. [PubMed: 18576604] (d) Kinzel T, Zhang Y, Buchwald SL. J Am Chem Soc. 2010; 132:14073. [PubMed: 20858009]

29. See Supporting Information for details.

30. The NMR analysis of the crude reaction mixture indicated $\sim 10 \%$ conversion to the $C 7^{\prime}$-linked regioisomer, and formation of a similar amount of the $\mathrm{C} 2^{\prime}$-linked regioisomer. HPLC purification was employed to separate the desired $\mathrm{C}^{\prime}$-linked product $(+)-19 \mathrm{a}$ from regioisomers.

31. This experiment also helped to identify mixtures of oligomers originating from tetracycle (+)-18a.

32. (a) Hino T, Taniguchi M, Yamamoto I, Nakagawa M. Tetrahedron Lett. 1981; 22:2565.(b) Taniguchi M, Yamamoto I, Nakagawa M, Hino T. Chem Pharm Bull. 1985; 33:4783.

33. (a) For an examples of the challenging N1 functionalization of related tetracyclic diketopiperazines, see ref. ${ }^{14} \mathrm{~d}$. For a difficult N1-aryl coupling, see Jabri SY, Overman LE. J Am Chem Soc. 2013; 135:4231. [PubMed: 23452064]

34. Major side products were the corresponding C2,C3-diastereomeric bromide and the C6-brominated tetracycle.

35. Takahashi M, Sengoku T, Yoda H, Murata Y, Yagishita F, Sakamoto M. Chem-Eur J. 2014; 20:11091. [PubMed: 25049083]

36. (a) Birkofer L, Bierwirth E, Ritter A. Chem Ber. 1961; 94:821.(b) Sakaitani M, Ohfune Y. J Org Chem. 1990; 55:870.

37. By comparison, tetra- $n$-butylammonium fluoride deprotection of the monomer (+)-30a was unproblematic, indicating that either the electron-withdrawing or conformational effects of the carboxybenzyl group in dimer (+)-31a could be responsible for epimerization.

38. Scheidt KA, Chen H, Follows BC, Chemler SR, Coffey DS, Roush WR. J Am Chem Soc. 1998; 63:6436.

39. (a) Magnus P, Gallagher T. J Chem Soc, Chem Comm. 1984:389.(b) Loegers M, Overman LE, Welmaker GS. J Am Chem Soc. 1995; 117:9139.(c) Boger DL, Keim H, Oberhauser B, Schreiner 
EP, Foster CA. J Am Chem Soc. 1999; 121:6197.(d) Somei M, Fukui Y, Hasegawa M, Oshikiri N, Hayashi T. Heterocycles. 2000; 53:1725.(e) Nakai, Y-y; Goto, A.; Yamada, F.; Somei, M. Heterocycles. 2003; 60:1589.(f) Calvert MB, Sperry J. Tetrahedron Lett. 2012; 53:5426.

40. Movassaghi M, Siegel DS, Han S. Chem Sci. 2010; 1:561. [PubMed: 21218186] 


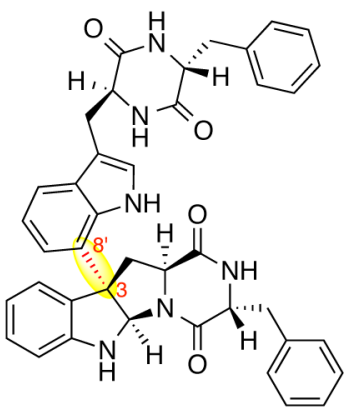

(+)-asperazine (1)

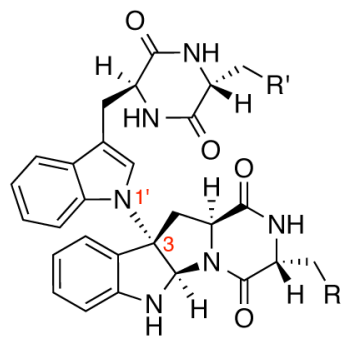

(-)-asperazine A (4a) $\left(\mathrm{R}, \mathrm{R}^{\prime}=\mathrm{Ph}\right)$

$(+)$-pestalazine $\mathrm{B}(\mathbf{4 b})$ $\left(\mathrm{R}=i-\mathrm{Pr}, \mathrm{R}^{\prime}=\mathrm{Ph}\right)$

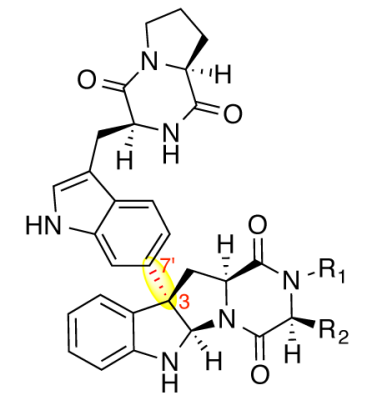

(+)-naseseazine $\mathrm{A}\left(\mathbf{5}, \mathrm{R}_{1}=\mathrm{H}, \mathrm{R}_{2}=\mathrm{Me}\right)$ $(+)$-naseseazine $B\left(6, R_{1} / R_{2}=\left(C_{2}\right)_{3}\right)$

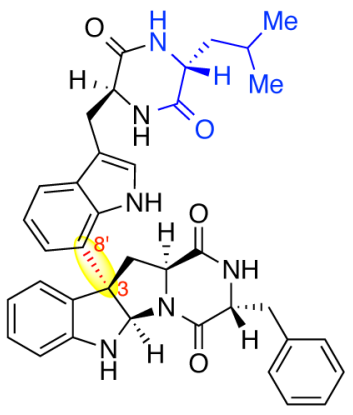

(+)-iso-pestalazine A (2) isolation report (ref. 4)

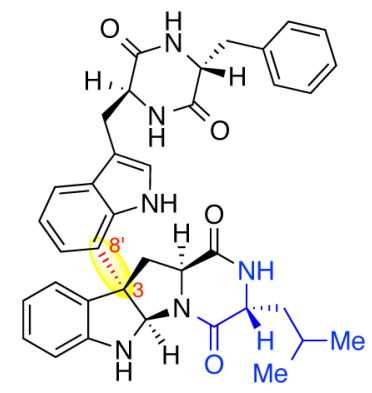

(+)-pestalazine A(3) revised structure (this report)

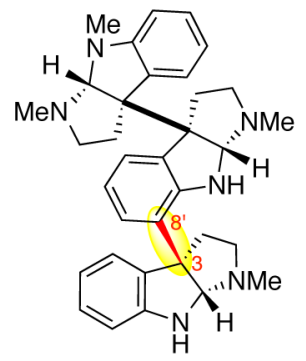

(-)-idiospermuline (7)

Figure 1.

Representative heterodimeric diketopiperazines. 


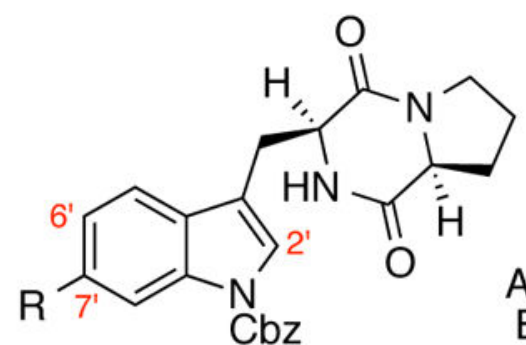<smiles>[As]P[Te]</smiles>

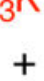

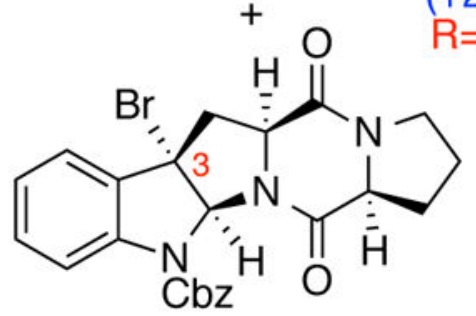

$(+)-10$

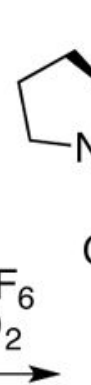

$\mathrm{R}=\mathrm{H}, 27 \%$ (+20\% isomer) $\mathrm{R}=\mathrm{BF}_{3} \mathrm{~K}, 50 \%$ $\mathrm{EtNO}_{2}$<smiles>CCC[C@@H]1NC[C@@H](C)C(=O)N1</smiles><smiles>[R]OC([R])([O-])N1C=C(CC)CC1</smiles><smiles>Cc1cccc([C@@]2(c3ccccc3)C[C@H]3C(=O)N4CCC[C@H]4C(=O)N3[C@@H]2Nc2ccccc2)c1</smiles>

(-)-11

$(+)$-naseseazine B (6) $\longleftarrow\left[\mathrm{H}_{2}\right]$

Scheme 1.

Concise Synthesis of the Naseseazines. 


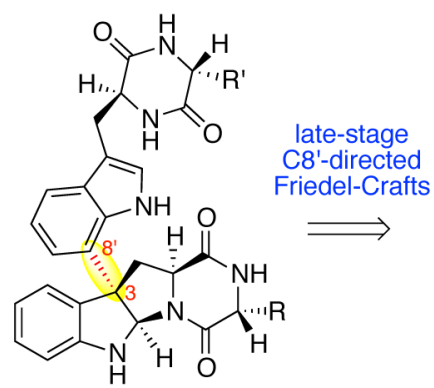

$(+)-1, R, R^{\prime}=B n$

$(+)-2, \mathrm{R}=\mathrm{Bn}, \mathrm{R}^{\prime}=i-\mathrm{Bu}$
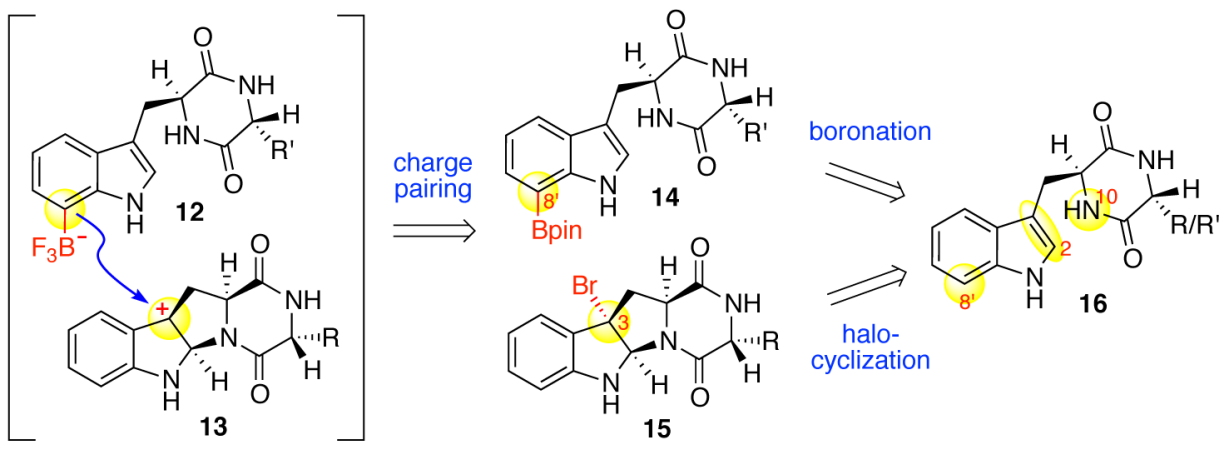

Scheme 2.

Initial Retrosynthetic Analysis of Alkaloids (+)-1 and (+)-2 based on C8-Boronated Tryptophan Synthesis. 

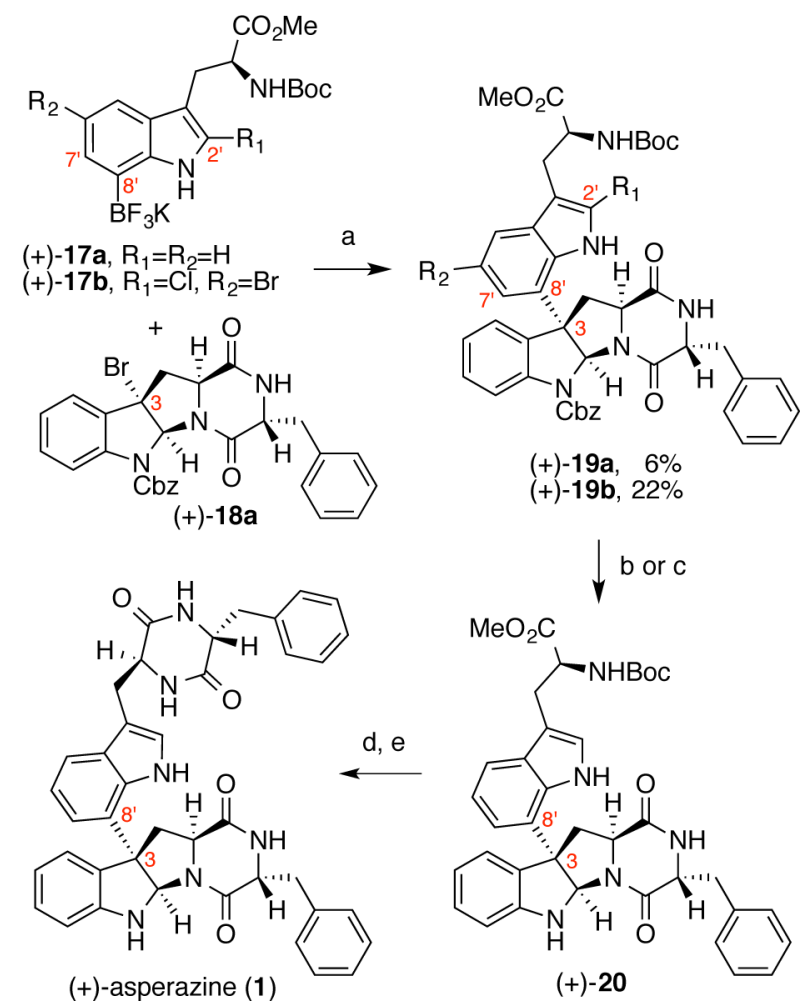

Scheme 3.

First Generation Synthesis of (+)-Asperazine (1). ${ }^{a}$

${ }^{a}$ Reagents and conditions: (a) $\operatorname{AgSbF}_{6}$ (2.0 equiv), DTBMP (2.2 equiv), 18-crown-6 (2.0 equiv), $\mathrm{EtNO}_{2}, 23{ }^{\circ} \mathrm{C}, 1$ h. (b) (+)-19a, $\mathrm{Pd} / \mathrm{C}(10 \%), \mathrm{H}_{2}$, EtOAc, 7 h, $23{ }^{\circ} \mathrm{C}, 81 \%$. (c) (+)-19b, $\mathrm{Pd} / \mathrm{C}(10 \%), \mathrm{NH}_{4} \mathrm{HCOO}, \mathrm{EtOH}, 70{ }^{\circ} \mathrm{C}, 7 \mathrm{~h}, 37 \%$. (d) TFA, $\mathrm{CH}_{2} \mathrm{Cl}_{2}, 23{ }^{\circ} \mathrm{C}, 2 \mathrm{~h}$; EDC.HCl, HOBt, Boc-D-Phe, $23{ }^{\circ} \mathrm{C}, 4$ h. (e) TFA, $\mathrm{CH}_{2} \mathrm{Cl}_{2}, 23{ }^{\circ} \mathrm{C}, 7 \mathrm{~h} ; n$-BuOH, $120{ }^{\circ} \mathrm{C}, 46$ h, $13 \%$ (over 2 steps). 
<smiles>[R7][C@@H]1NC(=O)[C@@H](Cc2c[nH]c3ccccc23)NC1=O</smiles>

$(+)-1, \mathrm{R}, \mathrm{R}^{\prime}=\mathrm{Bn}$

$(+)-2, \mathrm{R}=\mathrm{Bn}, \mathrm{R}^{\prime}=i-\mathrm{Bu}$<smiles></smiles>

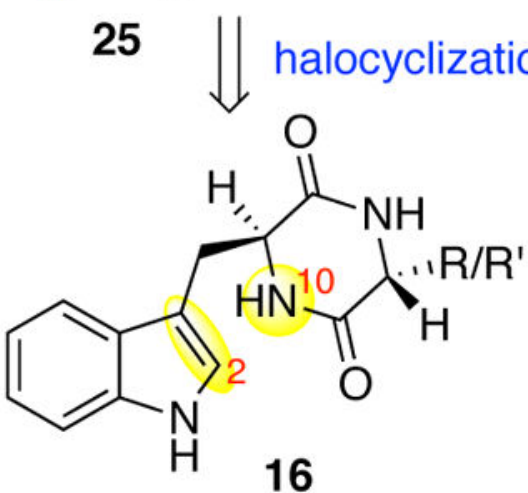

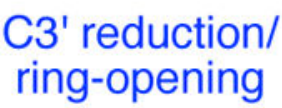

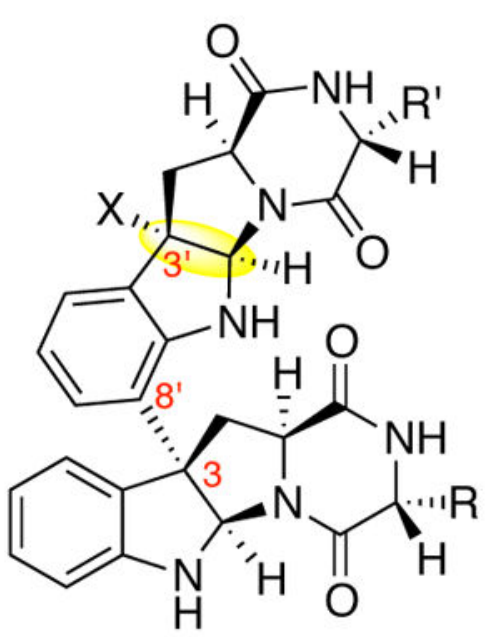

21, $\mathrm{X}=\mathrm{H}$

22, $\mathrm{X}=\mathrm{OH}$

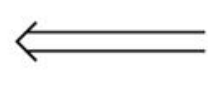

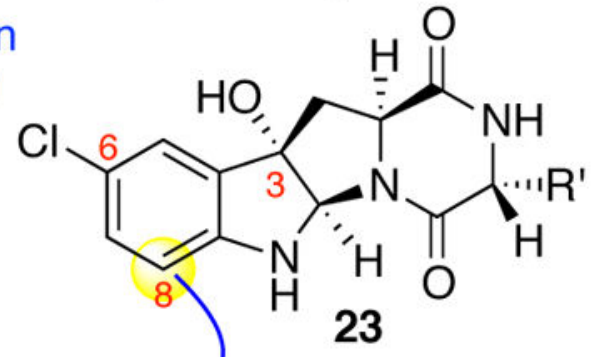

Scheme 4.

Revised Retrosynthetic Analysis of Alkaloids (+)-1 and (+)-2. 


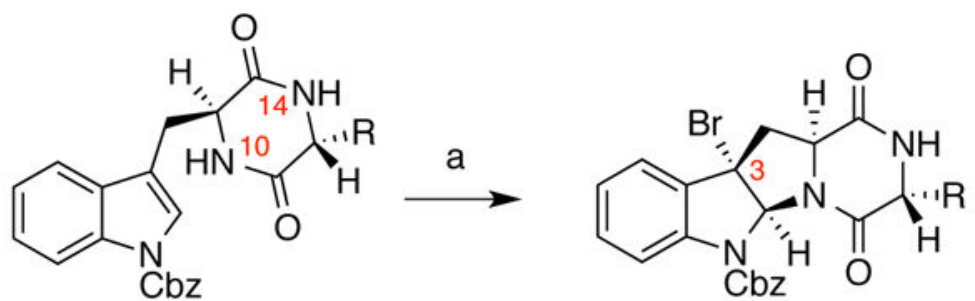

(+)-26a, $R=B n$

(+)-18a, $59 \%$

$(+)-26 \mathrm{~b}, \mathrm{R}=i-\mathrm{Bu}$

(+)-18b, 66\%

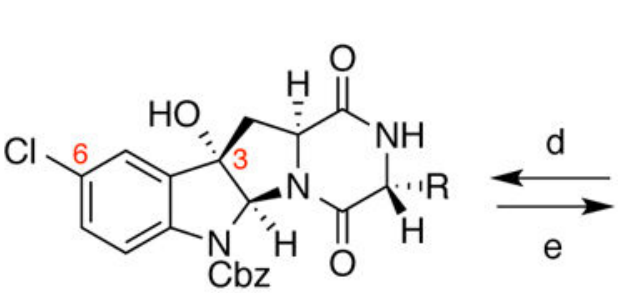

b or c $\downarrow$

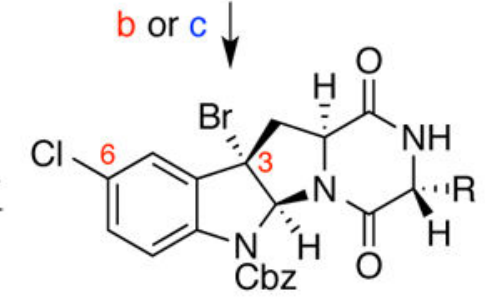

(+)-28a, $96 \%$

(+)-27a, $94 \%$

(+)-28b, 93\%

(+)-27b, 90\%

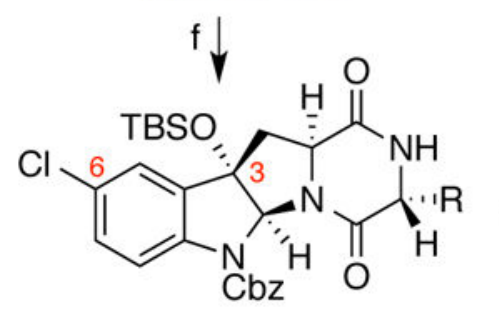

(+)-29a, $91 \%$

(+)-29b, $87 \%$

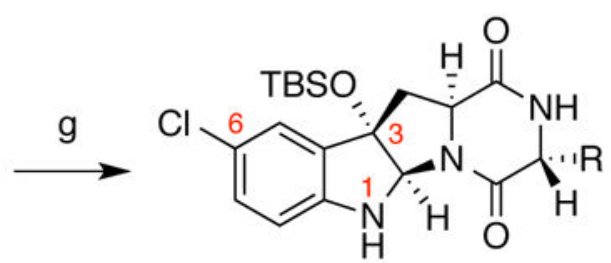

(+)-30a, R=Bn, 99\%

(+)-30b, $\mathrm{R}=i-\mathrm{Bu}, 90 \%$

Scheme 5.

Synthesis of Friedel-Crafts Components. ${ }^{a}$

${ }^{a}$ Reagents and conditions: (a) NBS, $\mathrm{BF}_{3} \cdot \mathrm{OEt}_{2}, \mathrm{MeCN}, 0{ }^{\circ} \mathrm{C}, 40 \mathrm{~min}$; (b) (+)-27a: NCS, TFA, MeCN, $23{ }^{\circ} \mathrm{C}, 20 \mathrm{~h}$; (c) (+)-27b: NCS, TiCl $, \mathrm{MeCN}^{\circ} 2{ }^{\circ} \mathrm{C}, 15 \mathrm{~h}$; (d) $\mathrm{AgSbF}_{6}, \mathrm{H}_{2} \mathrm{O}$, $\mathrm{EtNO}_{2}, 23{ }^{\circ} \mathrm{C}, 2 \mathrm{~h}$; (e) $\mathrm{SOBr}_{2}$, DTBMP, $\mathrm{CH}_{2} \mathrm{Cl}_{2}, 0{ }^{\circ} \mathrm{C}, 40 \mathrm{~min}$; (f) TBSOTf, 2,6-lutidine, $\mathrm{CH}_{2} \mathrm{Cl}_{2}, 23{ }^{\circ} \mathrm{C}, 35 \mathrm{~h}$; (g) $\mathrm{Pd}(\mathrm{OAc})_{2}, \mathrm{Et}_{3} \mathrm{SiH}, \mathrm{NEt}_{3}, \mathrm{CH}_{2} \mathrm{Cl}_{2}, 23{ }^{\circ} \mathrm{C}, 4 \mathrm{~h}$. 


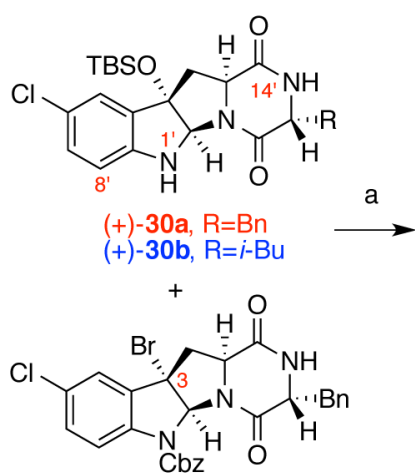

$(+)-27 a$

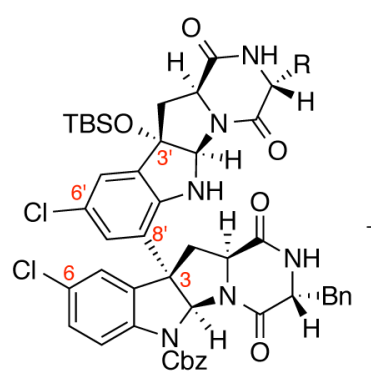

(+)-31a, $\mathrm{R}=\mathrm{Bn}, 41 \%$ (+)-31b, $\mathrm{R}=i-\mathrm{Bu}, 48 \%$

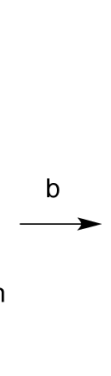

$$
\begin{aligned}
& \mathrm{R}=\mathrm{Bn} \text { : }{ }_{\mathrm{C}}(+)-32 \mathrm{a}, \mathrm{R}^{\prime}=\mathrm{TBS}, 79 \% \\
& \text { C } \longrightarrow \text { (+)-33a, R'=H, 90\% } \\
& \begin{array}{c}
\mathrm{R}=i-\mathrm{Bu}:(+)-32 \mathrm{~b}, \mathrm{R}^{\prime}=\mathrm{TBS}, 84 \% \\
\mathrm{~d}\left[-(+)-33 \mathrm{~b}, \mathrm{R}^{\prime}=\mathrm{H}, 91 \%\right.
\end{array}
\end{aligned}
$$

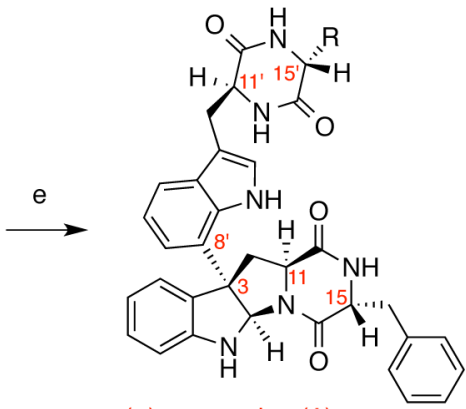

(+)-asperazine (1), $\mathrm{R}=\mathrm{Bn}, 67 \%$

(+)-iso-pestalazine A (2), $\mathrm{R}=i$-Bu, $73 \%$

Scheme 6.

Friedel-Crafts Reaction and Ring-Opening: Synthesis of (+)-Asperazine (1) and (+)-isoPestalazine A (2). ${ }^{a}$

${ }^{a}$ Reagents and conditions: (a) $\mathrm{AgSbF}_{6}$, DTBMP, EtNO $2,23{ }^{\circ} \mathrm{C}, 40 \mathrm{~min}$; (b) $\mathrm{Pd} / \mathrm{C}(10 \%)$, $\mathrm{HCO}_{2} \mathrm{NH}_{4}$, EtOH, $20 \mathrm{~h}, 70{ }^{\circ} \mathrm{C}$; (c) TASF, DMF, $23{ }^{\circ} \mathrm{C}, 40 \mathrm{~min}$; (d) TBAF, THF, $23{ }^{\circ} \mathrm{C}, 1 \mathrm{~h}$; (e) $\mathrm{MsOH}, \mathrm{Et}_{3} \mathrm{SiH}, \mathrm{CH}_{2} \mathrm{Cl}_{2}, 23{ }^{\circ} \mathrm{C}, 4 \mathrm{~h}$. 


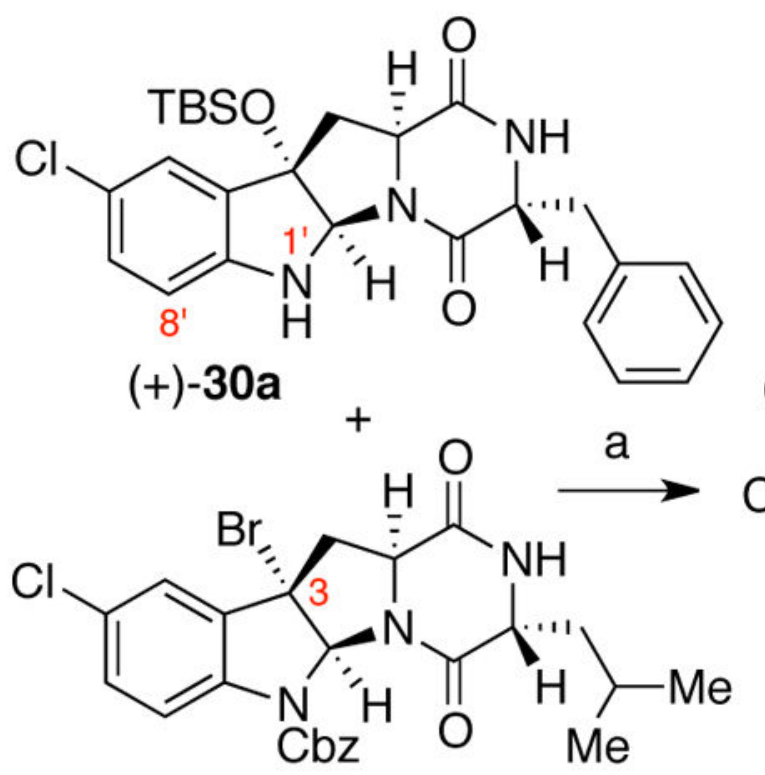

(+)-27b

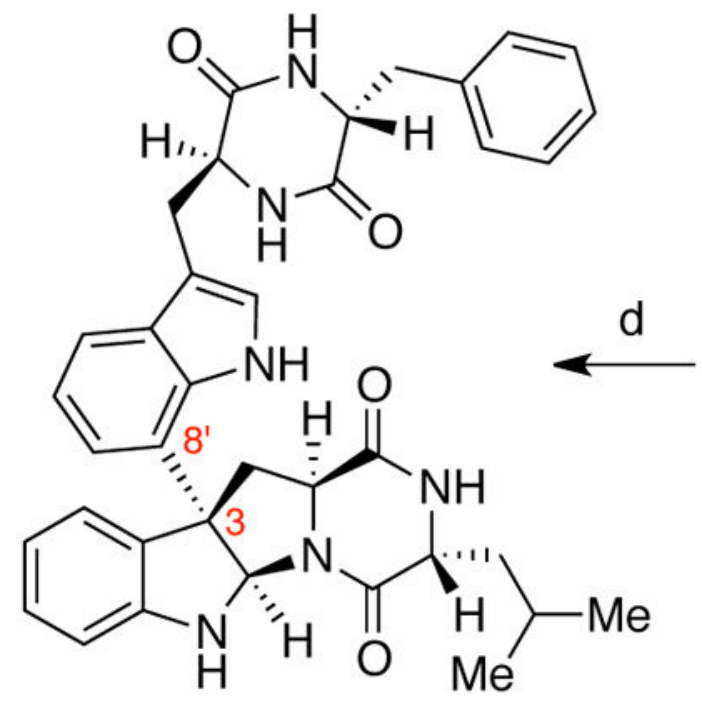

(+)-pestalazine A (3), $71 \%$

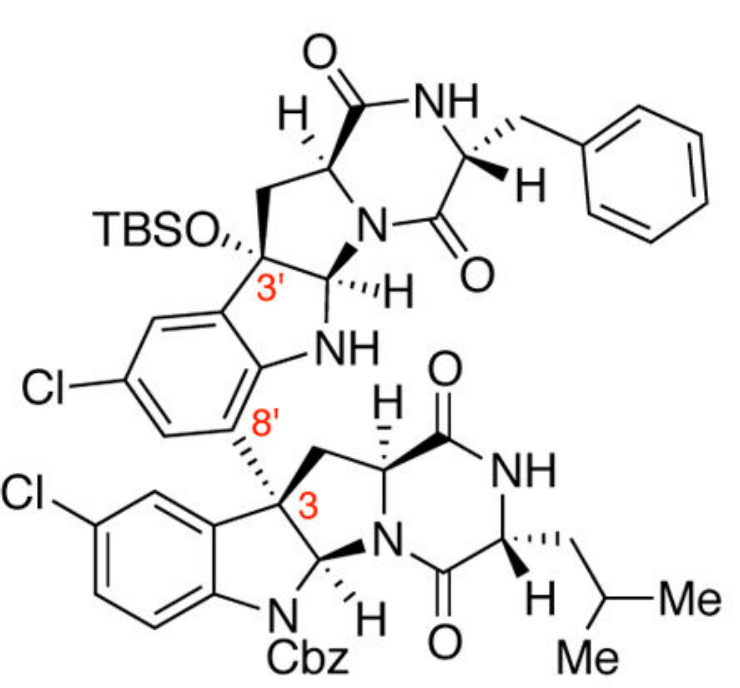

(+)-31c, $32 \%$

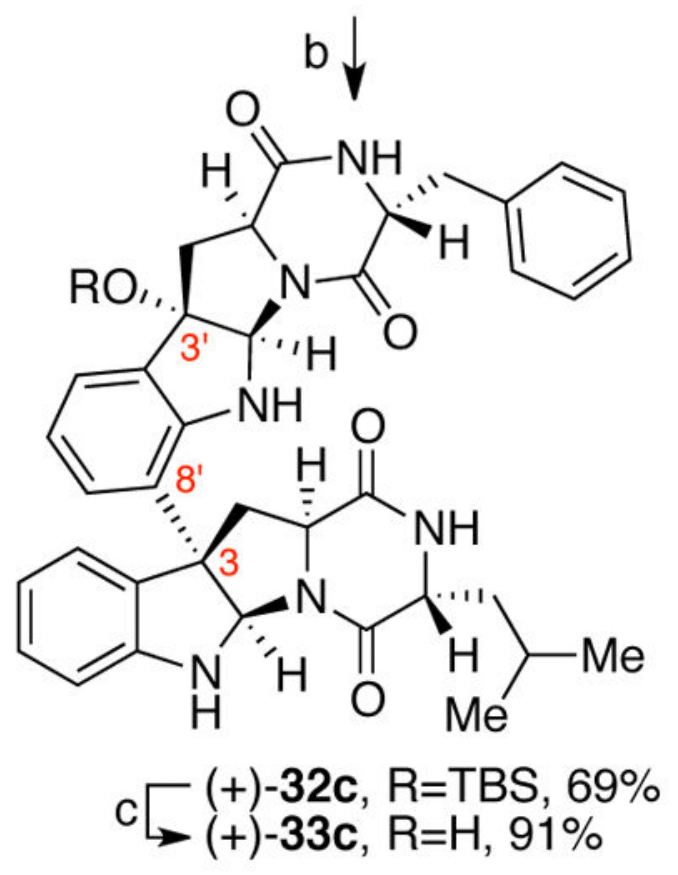

Scheme 7.

Synthesis of (+)-Pestalazine A (3) ${ }^{a}$

${ }^{a}$ Reagents and conditions: (a) $\mathrm{AgSbF}_{6}$, DTBMP, $\mathrm{EtNO}_{2} / \mathrm{CH}_{2} \mathrm{Cl}_{2}$ (3:1), $23{ }^{\circ} \mathrm{C}, 90 \mathrm{~min}$; (b)

$\mathrm{Pd} / \mathrm{C}(10 \%), \mathrm{HCO}_{2} \mathrm{NH}_{4}, \mathrm{EtOH}, 70{ }^{\circ} \mathrm{C}, 25 \mathrm{~h}$; (c) TASF, DMF, $23{ }^{\circ} \mathrm{C}, 1 \mathrm{~h}$; (d) $\mathrm{MsOH}, \mathrm{Et}_{3} \mathrm{SiH}$,

$\mathrm{CH}_{2} \mathrm{Cl}_{2}, 23{ }^{\circ} \mathrm{C}, 4 \mathrm{~h}$. 